\title{
Influence of lattice modifier on the nonlinear refractive index of tellurite glass
}

\author{
F.A. Santos ${ }^{\mathrm{a}}$, M.S. Figueiredo ${ }^{\mathrm{a}}$, E.C. Barbano ${ }^{\mathrm{b}}$, L. Misoguti ${ }^{\mathrm{b}}$, S.M. Lima ${ }^{\mathrm{c}}$, L.H.C. Andrade ${ }^{\mathrm{c}}$, \\ K. Yukimitu ${ }^{\mathrm{d}}$, J.C.S. Moraes ${ }^{\mathrm{d}, *}$ \\ a Grupo de Pesquisa de Materiais Fotônicos e Energia Renovável, Universidade Federal da Grande Dourados, Faculdade de Ciências Exatas e Tecnologia, \\ 79804-970 Dourados, MS, Brazil \\ b Instituto de Física de São Carlos - USP, 13566-590 São Carlos, SP, Brazil \\ c Grupo de Espectroscopia Óptica e Fototérmica, Universidade Estadual de Mato Grosso do Sul, CP 351, Dourados, MS, Brazil \\ ' Grupo Vidros e Cerâmicas, Faculdade de Engenharia de Ilha Solteira - UNESP, Ilha Solteira, SP, Brazil
}

\section{A R T I C L E I N F O}

\section{Keywords:}

Tellurite glass

Lattice modifier

Nonlinear refractive index

Structural change

Z-scan

\begin{abstract}
A B S T R A C T
We studied the influence of different lattice modifiers $\left(\mathrm{Nb}_{2} \mathrm{O}_{5}, \mathrm{Bi}_{2} \mathrm{O}_{3}\right.$, or $\left.\mathrm{TiO}_{2}\right)$ on the nonlinear refractive index of a tellurite glass matrix by using the $\mathrm{Z}$-scan technique. Based on the ability of the lattice modifiers to decrease the band-gap energy while simultaneously increasing the linear refractive index of the $\mathrm{TeO}_{2}$-based glass, we investigated how these modifiers affect the nonlinear refractive indices. All studied glass presented high nonlinearities, and the addition of lattice modifiers made only a small contribution to increasing magnitude. These results could be explained through the observation of the band-gap energy reduction, which is related to the increase in the non-bridging oxygen content with the addition of the lattice modifier. The increase in the refractive index nonlinearity is explained by the optical basicity and the high electronic polarizability of the modifiers ions.
\end{abstract}

\section{Introduction}

Third-order optical nonlinearities (TONL) of glass materials have been extensively studied, mainly due to their possible applications in telecommunications as ultrafast optical switches, modulators, and electro-optical devices [1-4]. Among several formed glass lattices, $\mathrm{TeO}_{2}$-based glass is receiving special attention due to its good optical properties, particularly when compared to traditional silicate glass, for instance. Apart from its high linear and nonlinear refractive indices, other important characteristics of this glass family are its low phonon energy, high infrared transmittance, and the possibility of second harmonic generation when an anisotropy is induced $[5,6]$.

The nature of the high-TONL properties of $\mathrm{TeO}_{2}$-based glass has been attributed to the high polarizability of a lone pair of electrons in the $\mathrm{Te}^{4+}$ ions, and a high percentage of $\mathrm{TeO}_{4}$ structural units present in glass lattice [7]. The lattice modifier plays an important role in the TONL properties, especially because it influences the glass structure, turning it with high hyperpolarizability [8].

The purpose of this work is to determine the nonlinear refractive index of tellurite glass prepared with different lattice modifiers by using a femtosecond Z-scan technique. The relationship among the obtained nonlinear refractive index with the linear refractive index, band gap energy, glass structure, optical basicity, and electronic polarizability are discussed.

\section{Experiment}

Tellurite glass was prepared by the conventional melting-quenching method from the following analytical grade reagents from SigmaAldrich ( $>99.99 \%$ purity): $\mathrm{TeO}_{2} ; \mathrm{Li}_{2} \mathrm{CO}_{3} ; \mathrm{Nb}_{2} \mathrm{O}_{5} ; \mathrm{Bi}_{2} \mathrm{O}_{3}$; and $\mathrm{TiO}_{2}$. Nine samples were prepared with the following compositions: $80 \mathrm{TeO}_{2}-$ $20 \mathrm{Li}_{2} \mathrm{O}, 80 \mathrm{TeO}_{2}-(20-\mathrm{x}) \mathrm{Li}_{2} \mathrm{O}-\mathrm{xNb}_{2} \mathrm{O}_{5}, 80 \mathrm{TeO}_{2}-(20-\mathrm{x}) \mathrm{Li}_{2} \mathrm{O}-\mathrm{xTiO}{ }_{2}$, and $80 \mathrm{TeO}_{2}-(20-\mathrm{x}) \mathrm{Li}_{2} \mathrm{O}-\mathrm{xBi}_{2} \mathrm{O}_{3}$ (with $\mathrm{x}=5,10$ or $15 \mathrm{~mol} \%$ ). For the glass containing Bismuth, the maximum $x$ value was $10 \mathrm{~mol} \%$, because we were unable to obtain glass material with $15 \mathrm{~mol} \%$, under the same experimental conditions. These samples will be referred to, henceforth, as TL, TLNx, TLTX, and TLBx, respectively. The reagents were weighed out, mixed in an agate mortar, and melted in a Pt-Au $5 \%$ crucible at $850^{\circ} \mathrm{C}$ for $60 \mathrm{~min}$. The melt was poured into a stainless steel mold preheated and annealed for $5 \mathrm{~h}$ at temperatures near the glass transition temperature $(\mathrm{Tg})$, which varies with the composition. Finally, the produced glass was cut and optically polished up to $\sim 1 \mathrm{~mm}$ thick.

\footnotetext{
* Correspondence to: Departamento de Física e Química, UNESP - Campus de Ilha Solteira, Av. Brasil 56, CEP 15385-000, Ilha Solteira, SP, Brazil.

E-mail address: joca@dfq.feis.unesp.br (J.C.S. Moraes).
} 
The X-ray diffraction pattern of all obtained samples showed the characteristic halo of an amorphous material.

Measurements of the nonlinear refractive index $\left(n_{2}\right)$ were carried out with the traditional closed-aperture single beam $\mathrm{Z}$-scan technique [9] using femtosecond laser pulses. A tunable optical parametric amplifier (OPA) was used as the excitation light source. It was pumped by a $\mathrm{Ti}^{3+}: \mathrm{Al}_{2} \mathrm{O}_{3}$ chirped pulse amplified system at $775 \mathrm{~nm}$ with approximately $150 \mathrm{fs}$ of duration and a repetition rate of $1 \mathrm{kHz}$. The OPA provided 120 -fs pulses from 0.46 to $2.6 \mu \mathrm{m}$. Here, the Z-scan measurements were performed using a laser radiation at $1.3 \mu \mathrm{m}$. A silica sample was used as reference to calibrate the magnitude of $n_{2}$ and to determine the Gaussian beam parameters. The laser beam passed by a spatial filter to ensure a Gaussian beam $\mathrm{TEM}_{00}$ profile, and it was focused by a lens $(f=15 \mathrm{~cm})$ at $z=0$. During the z-scan procedure, a translation stage moved the sample from $-z$ to $+z$ around the focus $(z=$ 0 ), and the transmitted signal passed through an aperture positioned in front of a large area germanium PIN photodetector, which was connected to a lock-in amplifier. In the open aperture configuration, it was possible to measure the imaginary part of the nonlinearity (twophoton absorption). To reduce the uncertainty in $n_{2}$ value due to laser fluctuation and sample inhomogeneity, at least three Z-scan measurements for each sample in different sample positions were performed.

The $n_{2}$ values obtained by Z-scan were compared with ones evaluated by the empirical expression from Hazarika-Rai [10] and Boling [11]. Although this method does not usually lead to the correct magnitudes of $n_{2}$, it can be used to indicate the correct trends of the nonlinearities as a function of linear optical parameter modifications.

A commercial spectrometer of the Varian 50 in the range of 190$1100 \mathrm{~nm}$ was used to measure the absorption spectra of the samples. The band-gap energy was evaluated from absorption spectra as proposed by Tauc [12]. The white-light Michelson interferometer was used to obtain the dispersion of the linear refractive index. The interference profile was detected by an Ocean Optics USB 2000 UVVIS+ES monochromator; the linear refractive index values, in the wavelength range $350-850 \mathrm{~nm}$, were estimated by the Cauchy equation [13]. The Raman scattering was recorded using $785 \mathrm{~nm}$ as excitation with a micro-Raman apparatus (BX51-Voyage model).

\section{Results and discussion}

Fig. 1 plots the refractive Z-scan signal obtained for the TLB10 glass at $1.3 \mu \mathrm{m}(0.03 \mathrm{~mW})$. Similar curves were also obtained for the other glass and for a silica sample (reference sample) used for experimental setup validation. This Z-scan signature of a valley followed by a peak indicates positive nonlinearity and is expected for a pure electronic effect. From the curve fit by the theoretical model proposed by Shake-

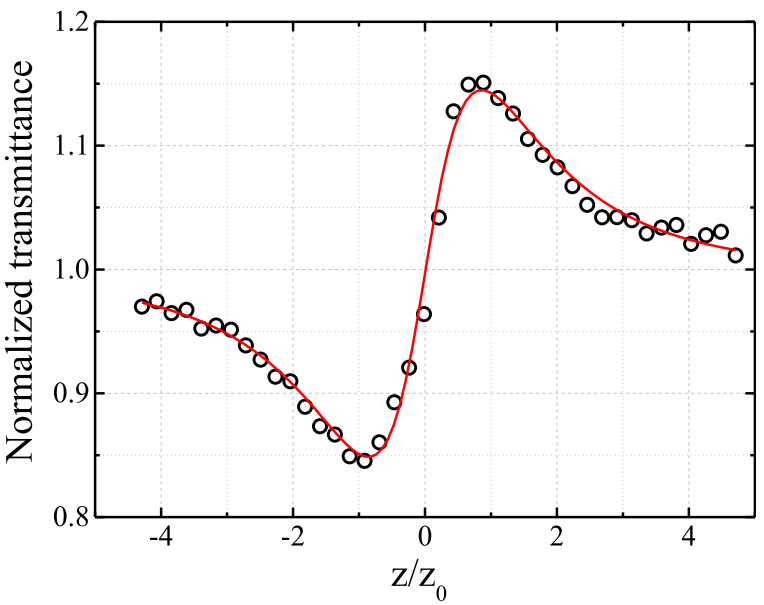

Fig. 1. Z-scan signal obtained for TLB10 glass by using $0.03 \mathrm{~mW}$ of a pulsed laser at $1.3 \mu \mathrm{m}$.
Table 1

Band-gap energy $\left(E_{\text {gap }}\right)$, experimental linear refractive index $\left(n_{\text {exp }}\right)$ at $632.8 \mathrm{~nm}$, calculated refractive index $\left(n_{\text {calc }}\right)$, polarizability $\left(\alpha_{O}^{2-}\right)$, basicity $(\Lambda)$, experimental nonlinear refractive index $\left(n_{2} \exp \right)$ measured at $1.3 \mu \mathrm{m}$, and nonlinear refractive index calculated by BGO theory $\left(n_{2 \text { calc }}\right)$.

\begin{tabular}{llllllll}
\hline Sample & $\begin{array}{l}E_{\text {gap }} \\
(\mathrm{eV})\end{array}$ & $\begin{array}{l}n_{\text {exp }} \\
( \pm 0.001)\end{array}$ & $n_{\text {calc }}$ & $\begin{array}{l}\alpha_{O}^{2-} \\
\left(\AA^{3}\right)\end{array}$ & $\Lambda$ & $\begin{array}{l}n_{2 \exp } \\
\left(10^{-19} \mathrm{~m}^{2} / \mathrm{W}\right)\end{array}$ & $\begin{array}{l}n_{\text {2calc }} \\
\left(10^{-19} \mathrm{~m}^{2} / \mathrm{W}\right)\end{array}$ \\
\hline TL & 3.43 & 1.985 & 2.06 & 2.31 & 0.973 & 2.6 & 5.0 \\
TLN5 & 3.14 & 2.090 & 2.08 & 2.31 & 0.974 & 2.9 & 5.1 \\
TLN10 & 3.04 & 2.160 & 2.14 & 2.33 & 0.982 & 3.0 & 5.5 \\
TLN15 & 3.00 & 2.210 & 2.36 & 2.35 & 0.989 & 3.5 & 6.5 \\
TLT5 & 2.98 & 2.062 & 2.12 & 2.31 & 0.976 & 2.9 & 5.6 \\
TLT10 & 2.93 & 2.132 & 2.15 & 2.32 & 0.979 & 2.9 & 6.8 \\
TLT15 & 2.90 & 2.161 & 2.17 & 2.32 & 0.981 & 3.1 & 8.0 \\
TLB5 & 3.28 & 2.045 & 2.08 & 2.31 & 0.976 & 2.8 & 6.0 \\
TLB10 & 3.21 & 2.099 & 2.11 & 2.34 & 0.990 & 3.0 & 7.2 \\
\hline
\end{tabular}

Bahae et. al. [14], $w_{0}=16 \mu \mathrm{m}$ and $\Delta \phi=0.156$ were determined. A value of $n_{2}=2.2 \times 10^{-20} \mathrm{~m}^{2} / \mathrm{W}$ was obtained for silica, whose value is strongly similar to the value reported in the literature [15]. By using the $n_{2}$ of fused silica as a reference, the average values of the nonlinear refractive indices for all studied tellurite glass were determined and are summarized in Table 1 . The estimated error $\left(0.2 \times 10^{-19} \mathrm{~m}^{2} / \mathrm{W}\right)$ was based on the fitting in our Z-scan measurements and from typical changes to experimental data due to laser intensity fluctuations. It is important to mention that the open aperture Z-scan measurements were also performed, but nonlinear absorption was not observed in any samples. The magnitude for the nonlinear refractive index is practically constant for the different lattice modifiers. However, slight growth trends with increases in modifier concentration can be seen, in which the TLN15 sample exhibits the highest $n_{2}$ value $\left(3.5 \times 10^{-19} \mathrm{~m}^{2} / \mathrm{W}\right)$. Our results are similar to those reported for TeZnNaNb, TeZnNaNbLa, $\mathrm{TeBa}, \mathrm{TeNb}$, and TeZnNaGe tellurite glass [16,17].

It is well known that band-gap energy $\left(E_{\text {gap }}\right)$ is an important parameter to describe the nature of the nonlinear refractive index and third-order nonlinear susceptibility $\chi^{(3)}$ [18]. Thus, the band gap energy of the glass was determined from the optical absorption coefficient $(\alpha)$ spectrum using the relation described by Tauc et al. [12]. Fig. 2 plots the $(\alpha E)^{1 / 2}$ spectra against the photon energy $(E)$ for TL, TLB5, and TLB10, showing the adopted procedure for evaluating $E_{\text {gap }}$. This procedure was also performed for all samples, and the obtained $E_{\text {gap }}$ values are presented in Table 1 . The results show that the concentration of the modifiers $\mathrm{Ti}, \mathrm{Nb}$, or Bi oxides cause a red shift in the cut-off edge when compared to the TL glass. Consequently, the band gap energy decreases when the modifier concentration increases.

This change in the absorption edge can result from the formation of non-bridging oxygen (NBO) in the glass structure [19] as has been

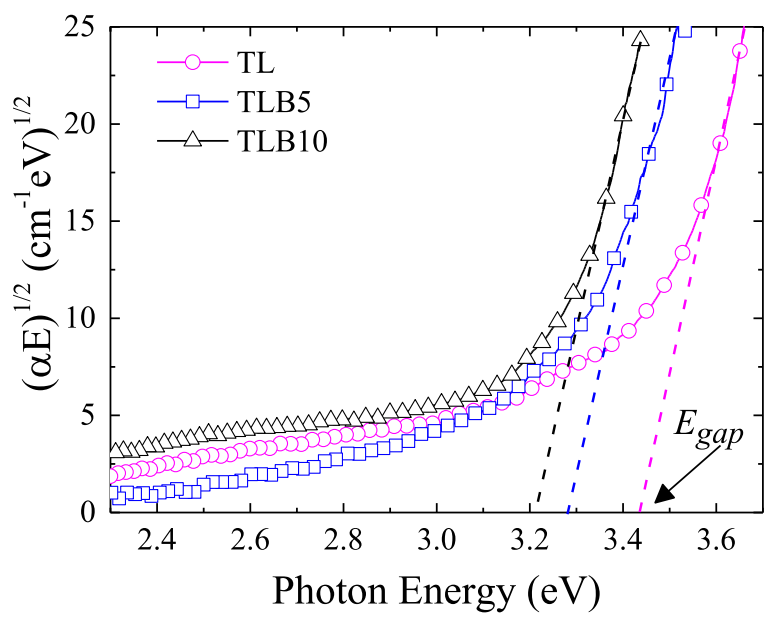

Fig. 2. $(\alpha E)^{1 / 2}$ vs. photon energy (E) spectra of the TL, TLB5, and TLB10 glass. 


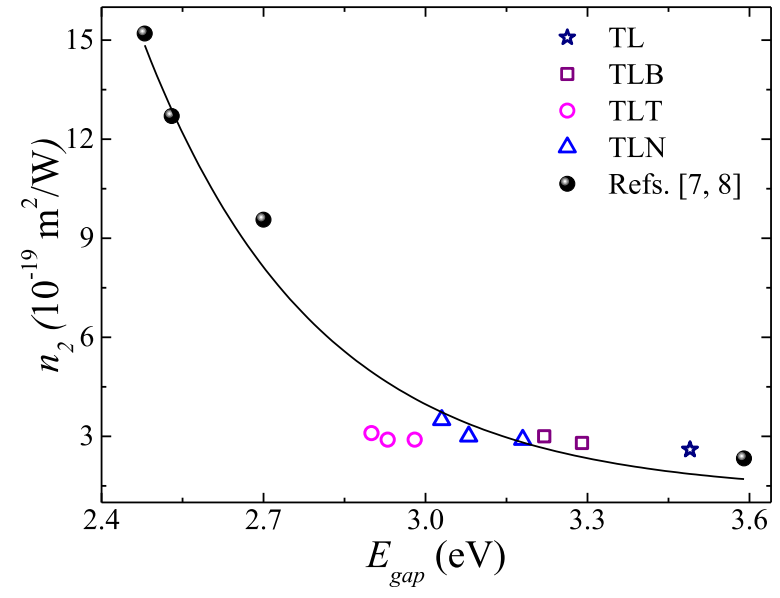

Fig. 3. Nonlinear refractive index as a function of the band gap energy. The solid line is included to aid visualization of the exponential behavior.

observed for several tellurite glass matrices, such as TeBiBa [20], TeLiB [21], and TeNbNa [22].

Fig. 3 shows the exponential dependence of the nonlinear refractive index on the band gap energy from tellurite glass reported in the literature $[7,8]$ together with the results obtained in this study. This exponential behavior obeys the relationship proposed by Sheik-Bahae et al. [23], and was also noted by Dimitrov and Sakka [18] when investigating a set of oxides. In this study, although the concentration range of $\mathrm{Ti}, \mathrm{Nb}$, and $\mathrm{Bi}$ changed the band gap energy, it was not important to alter the nonlinear refractive index values, as noted in Fig. 3.

Different authors report that the high polarizability of cations justifies the $n_{2}$ behavior with $E_{\text {gap }}$. On the other hand, El-Diasty et al. [24] argued that this is due to the increase in NBO that promotes unstable and weak linkages with former and modifier lattice atoms, meaning that the valence electrons can be easily distorted when exposed to the intense laser electric field.

Fig. 4 shows the refractive index dispersion for the TL, TLB5, TLB10, TLT10, and TLN10 samples, whose $n_{\text {exp }}$ values at $632.8 \mathrm{~nm}$ are displayed in Table 1 . The $n$ value increases when the concentration of the modifier oxide is increased. This increase in the $n_{\exp }$ values can be related to structural changes in the glass matrix when a lattice modifier is added, especially due the growth of the anionic quantities present in the glass lattice. In Capanema et al. [25], the relationship between the dispersion of the linear refractive index and the structural change was attributed to changes in the coordination number, which indicates the number of oxygen atoms neighboring the main cation. Likewise,

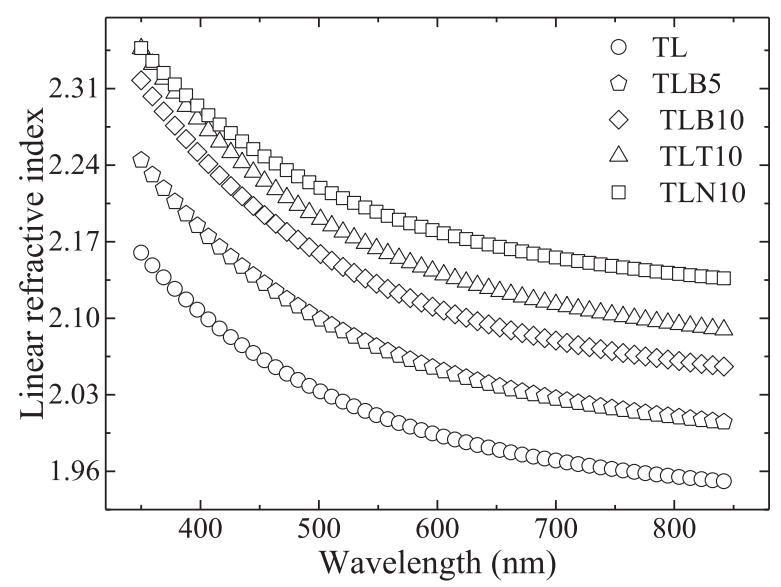

Fig. 4. Dispersion of the linear refractive index for the samples with different lattice modifiers.

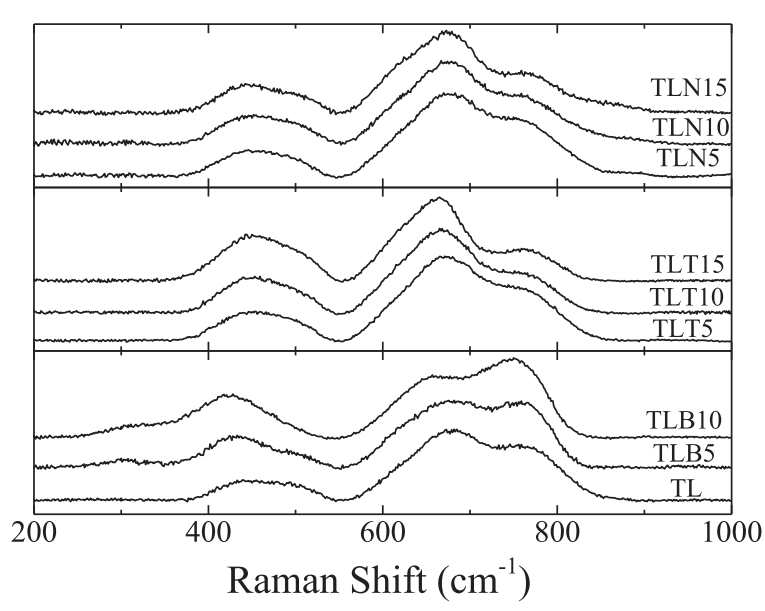

Fig. 5. Raman scattering for tellurite glass with different lattice modifiers.

Chagraoui et al. [26] measured the linear refractive index and verified that the lattice modifiers $\mathrm{ZnO}$ and $\mathrm{Bi}_{2} \mathrm{O}_{3}$ cause an increase in $n$ values. This was attributed to a structural change in the number of the NBO when higher $\mathrm{ZnO}$ and $\mathrm{Bi}_{2} \mathrm{O}_{3}$ amounts are introduced in the glass lattice. The values of the calculated refractive index $\left(n_{\text {calc }}\right)$ by the LorentzLorentz relationship [18] are shown in Table 1. Although the $n_{\text {calc }}$ values are slightly higher than the $n_{\exp }$ values, it is interesting to note the dependence with the modifier. This behavior was also observed in the nonlinear refractive index $n_{2}$ (listed in Table 1) determined from the dispersion of the linear refractive index using the Boling, Glass, and Owyoung (BGO) model [10,11].

In order to evaluate the vibrational characteristics of the TL glass with different lattice modifiers, Raman scattering measurements were performed in all studied samples. The spectra are showed in Fig. 5. A band at $442 \mathrm{~cm}^{-1}$ was identified by symmetrical stretching of linkages Te-O-Te [27], at $\sim 660 \mathrm{~cm}^{-1}$ to the Te-O-Te antisymmetric stretching vibration of $\mathrm{TeO}_{4}$ units, and at $750 \mathrm{~cm}^{-1}$ to the $\mathrm{Te}^{=} \mathrm{O}$ bonding, involving a three-coordinate tellurium atom $(\mathrm{O}=\mathrm{TeO} 2)$ [28]. It can be seen in the spectra that adding a lattice modifier to the TL glass matrix causes a structural change. For samples TLT5, TLT10, and TLT15, an increase in the band intensity centered at $660 \mathrm{~cm}^{-1}$ was observed, indicating a rising level of $\mathrm{TeO}_{4}$ structural units with the addition of $\mathrm{TiO}_{2}$. This is reinforced by a higher intensity band at $442 \mathrm{~cm}^{-1}$ of linkages Te-O-Te from $\mathrm{TeO}_{4}$ units. On the other hand, the band at $750 \mathrm{~cm}^{-1}$ shows a decrease in intensity. The same behavior in the function of concentration was observed for samples with niobium oxide.

When $\mathrm{Bi}_{2} \mathrm{O}_{3}$ was added, a structural change in TL glass due to a decrease in the intensity of the band centered at $660 \mathrm{~cm}^{-1}$ and an increase in the intensity of the band centered at $750 \mathrm{~cm}^{-1}$ was noted. This indicates that bismuth oxide is connected with glass lattice, causing elongation of the axial bonds of $\mathrm{TeO}_{4}$, transforming it at $\mathrm{TeO}_{3}$ through $\mathrm{TeO}_{3+1}$. This Raman band can be associated with the formation of the complex lattice $\mathrm{Bi}_{2} \mathrm{Te}_{4} \mathrm{O}_{11}$ [29]. This structural change is reinforced by the Raman spectral intensity of the band centered at $440 \mathrm{~cm}^{-1}$, which increases when higher $\mathrm{Bi}_{2} \mathrm{O}_{3}$ amounts are added to glass. In addition, the $\mathrm{Bi}_{2} \mathrm{O}_{3}$ displays a shift for lower wavenumbers, which characterizes the formation of Te-O-Bi linkages [19]. In this same context, the Raman spectra for samples with bismuth present a small band at $\sim 320 \mathrm{~cm}^{-1}$ that increases with $\mathrm{Bi}_{2} \mathrm{O}_{3}$. It corresponds to the $\mathrm{Bi}-\mathrm{O}-\mathrm{Bi}$ vibrations of the $\mathrm{BiO}_{6}$ octahedral units [19]. These results suggest that $\mathrm{Bi}_{2} \mathrm{O}_{3}$ in this amount plays the role of modifier in tellurite glass lattice and agree with the results presented by Fujiwara et al. [19] and Udovic et al. [30], which also suggest that bismuth is a latticeformer for higher $\mathrm{Bi}_{2} \mathrm{O}_{3}$ concentrations (> 20\% mol).

The increase in the $n_{2}$ for TL prepared with $\mathrm{Bi}_{2} \mathrm{O}_{3}$ may be associated with higher coordination numbers and ionic radii in $\mathrm{Bi}^{3+}$ ions (1.2 $\AA$ ), 
which increase the number of NBO [31]. In accordance with Reddy et al. [32], oxide ions such as $\mathrm{Cd}^{2+}, \mathrm{Ba}^{2+}, \mathrm{Sb}^{3+}$, and $\mathrm{Bi}^{3+}$ present a high electronic polarizability that is related to large ionic radii and field strength of the cationic unit. To confirm this hypothesis, optical basicity $(\Lambda)$ and polarizability $\left(\alpha_{O}^{2-}\right)$ were determined by the Duffy and Ingram model [33]. The optical basicity measures the negative charge donate power from the oxygen ion to the glass lattice, meaning that it should indicate the influence of the lattice modifiers on the covalence of the glass. The results are shows in Table 1 , and reveal that $\Lambda$ and $\alpha_{O}{ }^{2-}$ increase with lattice modifiers as expected, since these parameters are directly related. The increase in the $\Lambda$ values suggests that the glass structure is more depolymerized, and, consequently, an increase in the NBO linkages can be observed. Since NBO possesses high electronic polarizability, glass with a high NBO value can indicate an increase in the TONL optical properties.

\section{Conclusions}

In summary, different TeO2-based glass was prepared and its optical and structural properties investigated. Nonlinear refractive index results show an increase in $n_{2}$ values for all samples when lattice modifiers are added; the highest value was obtained for $65 \mathrm{TeO}_{2}+20 \mathrm{Li}_{2} \mathrm{O}+15 \mathrm{Nb}_{2} \mathrm{O}_{5}$ glass. The results reveal that the addition of $\mathrm{TiO}_{2}, \mathrm{Nb}_{2} \mathrm{O}_{5}$, and $\mathrm{Bi}_{2} \mathrm{O}_{3}$ in TL glass increases the values of $E_{g}$ and $n$, mainly due to structural changes. The obtained results for the different lattice modifiers in TL glass present a good correlation between $n_{2}, E_{g}$ and $n_{\exp }$ values, as well as with structural changes. The increase in the TONL properties are strongly related with structural changes, a phenomenon that is confirmed by the optical basicity and polarizability values associated with $\mathrm{NBO}$ linkages, as well as $\mathrm{Te}^{4+}$ ions.

\section{Acknowledgments}

The authors are grateful to the Brazilian agencies Capes, CNPq, FUNDECT, and FAPESP.

\section{References}

[1] C. Quemard, F. Smektala, V. Courdec, A. Barthelemy, J. Lucas, Chalcogenide glasses with high nonlinear optical properties for telecommunications, J. Phys. Chem. Solids 62 (2001) 1435-1440.

[2] J.M.P. Almeida, L. De Boni, A.C. Hernandes, C.R. Mendonça, Third-order nonlinear spectra and optical limiting of lead oxifluoroborate glasses, Opt. Express 19 (2011) 17220-17225.

[3] Y. Xu, H. Zeng, G. Yang, G. Chen, Q. Zhang, L. Xu, Third-order nonlinearities in $\mathrm{GeSe}_{2}-\mathrm{In}_{2} \mathrm{Se}_{3}$-CsI glasses for telecommunications applications, Opt. Mater. 31 (2008) 75-78.

[4] J.M.P. Almeida, D.S. Silva, L.R.P. Kassab, S.C. Zilio, C.R. Mendonça, L. De Boni, Ultrafast third-order optical nonlinearities of heavy metal oxide glasses containing gold nanoparticles, Opt. Mater. 36 (2014) 829-832.

[5] R.A.H. Mallawany, Tellurite Glasses Handbook: Physical Properties and Data, 2nd ed., CRC Press LLC, USA, 2002.

[6] E. Yousef, M. Hotzel, C. Rüssel, Linear and non-linear refractive indices of tellurite glasses in the system $\mathrm{TeO}_{2}-\mathrm{WO}_{3}-\mathrm{ZnF}_{2}$, J. Non-Cryst. Solids 342 (2004) 82-88.

[7] Y. Chen, Q. Nie, T. Xu, S. Dai, X. Wang, X. Shen, A study of nonlinear optical properties in $\mathrm{Bi}_{2} \mathrm{O}_{3}-\mathrm{WO}_{3}-\mathrm{TeO}_{2}$, J. Non-Cryst. Solids 354 (2008) 3468-3472.

[8] R. Castro-Beltran, H. Desirena, G. Ramos-Ortiz, E. De La Rosa, G. Lanty, J.S. Lauret, S. Romero-Servin, A. Schulzgen, Third-order nonlinear optical response and photoluminescence characterization of tellurite glasses with different alkali metal oxides as network modifiers, J. Appl. Phys. 110 (2011) 083110.

[9] M. Sheik-Bahae, A.A. Said, E.W. Van Stryland, High-sensitivity, single-beam n2 measurements, Opt. Lett. 14 (1989) 955-957.

[10] S. Hazarika, S. Rai, Characteristics of $\mathrm{Nd}^{3+}$ ions in sol-gel derivate silicate glass in presence of $\mathrm{Al}\left(\mathrm{NO}_{3}\right)_{3}$ and the ${ }^{4} \mathrm{~F}_{3 / 2} \rightarrow{ }^{4} \mathrm{I}_{11 / 2}$ transition, Opt. Mater. 30 (2007) $462-467$.

[11] N.L. Boling, A.J. Glass, A. Owyoung, Empirical relationships for predicting nonlinear refractive index changes in optical solids, IEEE J. Quantum Electron. QE14 (1978) 601.

[12] J. Tauc, R. Grigorocivi, A. Vancu, Optical properties and electronic structure of amorphous germanium, Phys. Status Solidi 15 (1966) 627-637.

[13] A.C.P. Rocha, J.R. Silva, L.A.O. Nunes, S.M. Lima, L.H.C. Andrade, Measurements of refractive indices and thermo-optical coefficients using a white-light Michelson interferometer, Appl. Opt. 55 (2016) 6639-6643.

[14] M. Sheik-Bahae, A.A. Said, T. Wei, D.J. Hagan, E.W. Van Stryland, Sensitive measurement of optical nonlinearities using a single beam, IEEE J. Quant. Electron. 26 (1990) 760-769.

[15] R. De Salvo, A.A. Said, D.J. Hagan, E.W. Van Stryland, M. Sheik-Bahae, Infrared to ultraviolet measurements of two-photon absorption and n2 in wide bandgap solid, IEEE J. Quant. Electron. 32 (1996) 1324-1333.

[16] F.E.P. dos Santos, F.C. Fávero, A.S.L. Gomes, J. Xing, Q. Chen, M. Fokine, C.S. Carvalho, Evaluation of the third-order nonlinear optical properties of tellurite glasses by thermally managed eclipse Z -scan, J. Appl. Phys. 105 (2009) 024512.

[17] R.F. Souza, M.A.R.C. Alencar, J.M. Hickmann, R. Kobayashi, L.R.P. Kassab, Femtosecond nonlinear optical properties of tellurite glasses, Appl. Phys. Lett. 89 (2006) 171917.

[18] V. Dimitrov, S. Sakka, Linear and nonlinear optical properties of simple oxides. II, J. Appl. Phys. 79 (1996) 1741-1745.

[19] T. Fujiwara, T. Hayakawa, M. Nogami, P. Thomas, Structures and third-order optical nonlinearities of $\mathrm{BiO}_{1.5}-\mathrm{WO}_{3}-\mathrm{TeO}_{2}$ glasses, J. Am. Ceram. Soc. 94 (2011) $1434-1439$.

[20] T. Xu, F. Chen, S. Dai, X. Shen, X. Wang, Q. Nie, C. Liu, K. Xu, J. Heo, Glass formation and third-order nonlinear properties within $\mathrm{TeO}_{2}-\mathrm{Bi}_{2} \mathrm{O}_{3}-\mathrm{BaO}$ pseudoternary system, J. Non-Cryst. Solids 357 (2011) 2219-2222.

[21] N. Elkhoshkhany, R. El-Mallawany, Optical and kinetics parameters of lithium boro-tellurite glasses, Ceram. Int. 41 (2015) 3561-3567.

[22] G. Vijaya Prakash, D. Narayana Rao, A.K. Bhatnagar, Linear optical properties of niobium-based tellurite glasses, Solid State Commun. 119 (2001) 39-44.

[23] M. Sheik-Bahae, D.J. Hagan, E.W. Van Stryland, Dispersion and band-gap scaling of the electronic Kerr effect in solids associated with two-photon absorption, Phys. Rev. Lett. 65 (1990) 96-99.

[24] F. El-Diasty, M. Abdel-Baki, F.A. Abdel-Wahab, Tuned intensity-dependent refractive index $\mathrm{n}_{2}$ and two-photon absorption in oxide glasses: role of nonbridging oxygen bonds in optical nonlinearity, Opt. Mater. 31 (2008) 161-166.

[25] W.A. Capanema, K. Yukimitu, J.C.S. Moraes, F.A. Santos, M.S. Figueiredo, S.M. Sidel, V.C.S. Reynoso, O. Sakai, A.N. Medina, The structure and optical dispersion of the refractive index of tellurite glass, Opt. Mater. 33 (2011) $1569-1572$.

[26] A. Chagraoui, A. Chakib, A. Mandil, A. Tairi, Z. Ramzi, S. Benmokhtar, New investigation within $\mathrm{ZnO}-\mathrm{TeO}_{2}-\mathrm{Bi}_{2} \mathrm{O}_{3}$ system in air, Scr. Mater. 56 (2007) 93-96.

[27] A.G. Kalampounias, Low-frequency Raman scattering in alkali tellurite glasses, Bull. Mater. Sci. 31 (2008) 781-785.

[28] V.O. Sokolov, V.G. Plotnichenko, E.M. Dianov, Structure of $\mathrm{WO}_{3}-\mathrm{TeO}_{2}$ glasses, Inorg. Mater. 33 (2007) 194-213.

[29] M. Udovic, P. Thomas, A. Mirgorodsky, O. Durand, M. Soulis, O. Masson, T. MerleMejean, J.C. Chaparnaud-Mesjard, Thermal characteristics, Raman spectra and structural properties of new tellurite glasses within the $\mathrm{Bi}_{2} \mathrm{O}_{3}-\mathrm{TiO}_{2}-\mathrm{TeO}_{2}$ system, J. Solid State Chem. 179 (2006) 3252-3259.

[30] R.S. Kundu, S. Dhankhar, R. Punia, K. Nanda, N. Kishore, Bismuth modified physical, structural and optical properties of mid-IR transparent zinc boro-tellurite glasses, J. Alloy. Compd. 587 (2014) 66-73.

[31] T. Hasegawa, T. Nagashima, N. Sugimoto, Z-scan study of third-order optical nonlinearities in bismuth-based glasses, Opt. Commun. 250 (2005) 411-415.

[32] R.R. Reddy, Y. Nazer Ahammed, P. Abdul Azeem, K. Rama Gopal, T.V.R. Rao Electronic polarizability and optical basicity properties of oxide glasses through average electronegativity, J. Non-Cryst. Solids 286 (2001) 169-180.

[33] J.A. Duffy, D. Ingram, An interpretation of glass chemistry in terms of the optical basicity concept, J. Non-Cryst. Solids 21 (1976) 373-410. 